\title{
Regional grey matter volumetric changes in forensic schizophrenia patients: a magnetic resonance imaging study comparing the brain structure of patients who have seriously and violently offended with those of patients who have not
}

\author{
Basant K Puri ${ }^{1}$, Serena J Counsell ${ }^{1}$, Nadeem Saeed ${ }^{1}$, Marcelo G Bustos ${ }^{2}$, Graeme M Bydder ${ }^{3}$, Ian H Treasaden $^{4^{*}}$ \\ From $1^{\text {st }}$ International Congress on Neurobiology and Clinical Psychopharmacology \\ and European Psychiatric Association Conference on Treatment Guidance \\ Thessaloniki, Greece. 19-22 November 2009
}

\section{Background}

The aim of this study was to carry out the first voxelbased morphometry study of grey matter changes in the whole brain in schizophrenia associated with a history of seriously and violently offending.

\section{Materials and methods}

Structural cerebral MRI scans of 26 patients with schizophrenia were analyzed using voxel-based morphometry: 13 of the patients had seriously and violently offended directly as a result of schizophrenia prior to admission, the offences consisting of homicide, attempted murder or wounding with intent to cause grievous bodily harm; the other 13 patients did not have a history of violence. There was no history of comorbid psychoactive substance misuse disorder in any of the patients. Voxelwise generalized linear modelling was applied to the processed magnetic resonance data using permutation-based non-parametric testing, forming clusters at $t>2.3$ and testing clusters for significance at $\mathrm{p}<0.05$, corrected for multiple comparisons across space.

${ }^{4}$ Head of Forensic Neurosciences, Lipid Neuroscience Group, Imperia College London and Three Bridges Medium Secure Unit, West London Mental Health NHS Trust, Middlesex, UK

\section{Results}

The two groups were matched with respect to age, gender and illness duration, but the group with a history of serious violence was on average receiving a higher dose of antipsychotic medication than the other group. There were local regions of reduced grey matter volume in the group with a history of serious and violent offending, compared with the other group without such a history. Significant voxels $(p<0.05$, corrected for multiple comparisons) were noted bilaterally in the cerebellum and in BA 39 and 40.

\section{Conclusions}

These regions are important in verbal working memory. The cerebellum may integrate inputs from ventrolateral prefrontal cortex and parietal regions, providing a corrective signal that refines the process of rehearing the contents of the phonological store. A strong connection has been hypothesized between the supramarginal region corresponding to BA 39/40 and Broca's area, which may correspond largely to the arcuate fasciculus, with the connectional pattern of the language regions of this model fitting the network of parietotemporal-prefrontal connections that participate in working memory. Therefore our results point to the possibility of an 
abnormality in neural circuits involved in verbal working memory in this group of patients.

\section{Acknowledgements}

We thank the Three Bridges Medium Secure Unit and the MRC.

\section{Author details}

'Imaging Sciences Department, Hammersmith Hospital, Imperial College London, UK. ${ }^{2}$ Three Bridges Medium Secure Unit, West London Mental Health NHS Trust, Middlesex, UK. ${ }^{3}$ Department of Radiology, University of California, San Diego, School of Medicine, San Diego, CA, USA. ${ }^{4}$ Head of Forensic Neurosciences, Lipid Neuroscience Group, Imperial College London and Three Bridges Medium Secure Unit, West London Mental Health NHS Trust, Middlesex, UK.

Published: 22 April 2010

doi:10.1186/1744-859X-9-S1-S154

Cite this article as: Puri et al:: Regional grey matter volumetric changes

in forensic schizophrenia patients: a magnetic resonance imaging study comparing the brain structure of patients who have seriously and violently offended with those of patients who have not. Annals of General Psychiatry 2010 9(Suppl 1):S154.

\section{Submit your next manuscript to BioMed Central} and take full advantage of:

- Convenient online submission

- Thorough peer review

- No space constraints or color figure charges

- Immediate publication on acceptance

- Inclusion in PubMed, CAS, Scopus and Google Scholar

- Research which is freely available for redistribution

Submit your manuscript at www.biomedcentral.com/submit 